Pathologe 2021 · 42:172-182 https://doi.org/10.1007/s00292-021-00924-x Angenommen: 15. Januar 2021 Online publiziert: 1. März 2021

() Der/die Autor(en) 2021

Schwerpunktherausgeber

W. Roth, Mainz

P. Boor, Aachen

Eine sichere ätiologische Zuordnung der unterschiedlichen neurologischen Symptome bei Patienten mit SARS-CoV-2-Infektionen ist bisher nicht immer möglich, insbesondere, ob es sich um primär virusinduzierte, autoimmunassoziierte oder sekundäre Veränderungen handelt. Feingewebliche Untersuchungen können helfen, die zugrunde liegenden Mechanismen besser zu verstehen. Daher ist es dringend erforderlich, auch weiterhin Obduktionen von verstorbenen COVID19-Patienten durchzuführen. Die neuropathologische Untersuchung von Gewebe aus Zentralnervensystem und peripherem Nervensystem kann hierbei wichtige Erkenntnisse

N. Ritschel und H. Radbruch sowie T. Acker und A. Németh haben jeweils gleichermaßen zu dem Manuskript beigetragen.

Die Mitglieder der DGNN-Taskforce CNS-COVID19 als auch der DEFEATPANDEMICS Neuropathologische Referenzdiagnostik bei COVID-19 werden jeweils am Beitragsende gelistet.

N. Ritschel $\cdot$ H. Radbruch ${ }^{2} \cdot$ C. Herden ${ }^{3} \cdot$ N. Schneider ${ }^{4} \cdot$ C. Dittmayer ${ }^{2} \cdot$ J. Franz ${ }^{5}$.

C. Thomas ${ }^{5} \cdot$ G. Silva Boos ${ }^{3} \cdot$ A. Pagenstecher ${ }^{6} \cdot$ W. Schulz-Schaeffer ${ }^{7} \cdot$

C. Stadelmann ${ }^{5} \cdot$ M. Glatzel ${ }^{8} \cdot$ F. L. Heppner ${ }^{2,9,10} \cdot$ J. Weis $^{11} \cdot$ K. Sohrabi $^{12}$.

A. Schänzer ${ }^{1} \cdot$ A. Németh ${ }^{1} \cdot$ T. Acker ${ }^{1}$. DGNN-Taskforce "CNS-COVID19“ • „DEFEAT PANDEMIcs - Neuropathologische Referenzdiagnostik bei COVID-19“"

${ }^{1}$ Institut für Neuropathologie, Justus-Liebig-Universität Gießen, Gießen, Deutschland

${ }^{2}$ Institut für Neuropathologie, Charité - Universitätsmedizin Berlin, Berlin, Deutschland

${ }^{3}$ Institut für Veterinär-Pathologie, Justus-Liebig-Universität Gießen, Gießen, Deutschland

${ }^{4}$ Institut für Medizinische Informatik, Justus-Liebig-Universität Gießen, Gießen, Deutschland

${ }^{5}$ Institut für Neuropathologie, Universitätsmedizin Göttingen, Göttingen, Deutschland

${ }^{6}$ Abteilung für Neuropathologie, Philipps-Universität Marburg, Marburg, Deutschland

${ }^{7}$ Institut für Neuropathologie, Universität des Saarlandes, Homburg, Deutschland

${ }^{8}$ Institut für Neuropathologie, Universitätsklinikum Hamburg-Eppendorf (UKE), Hamburg, Deutschland

${ }^{9}$ Exzellenzcluster NeuroCure, Berlin, Deutschland

${ }^{10}$ Deutsches Zentrum für Neurodegenerative Erkrankungen (DZNE), Berlin, Deutschland

"Institut für Neuropathologie, Universitätsklinikum der RWTH Aachen, Aachen, Deutschland

${ }^{12}$ Fachbereich Gesundheit, Technische Hochschule Mittelhessen, Gießen, Deutschland

\title{
COVID-19: Auswirkungen auf das zentrale und periphere Nervensystem
}

zum Verständnis der neurologischen Symptome liefern und Therapieentscheidungen verbessern.

\section{Neuropathologische} Manifestationen einer SARSCoV-2-Infektion

\section{Zentrales Nervensystem (ZNS)}

Eine SARS-CoV-2-Infektion kann mit einem breiten Spektrum neurologischer Komplikationen assoziiert sein [44]. In Autopsiestudien konnte gezeigt werden, dass vor allem zerebrovaskuläre Ereignisse wie ischämische Infarkte, verursacht durch Mikrothromben oder eine Schädigung der zerebralen Gefäße, auftreten können (『Tab. 1). Bei Betrachtung der größeren neuropathologischen Studien $[14,37-38,48,51]$ zeigen sich bei ca. $13 \%$ der Autopsien fokale Infarkte. Im klinischen Kontext konnte die SARS-CoV2-Infektion als unabhängiger Schlaganfall-Risikofaktor identifiziert werden [2]. Überdies zeigt eine aktuelle klinische Metaanalyse von akuten zerebralen Schlag- anfällen eine Inzidenz von 1,4\%. Dabei sind diese am häufigsten mit akuten ischämischen Infarkten assoziiert (87\%) [41]. Jedoch ist die zerebrale Hypoxie in neuropathologischen Studien nicht immer einheitlich definiert, wobei globale hypoxisch-ischämische Zustände, möglicherweise als Folge einer respiratorischen Insuffizienz bei COVID-19, von fokalen zerebralen thrombembolischen Ereignissen zu unterscheiden sind.

Entzündungen des ZNS sind nur in einzelnen Fällen in Form einer Meningoenzephalitis oder eines ADEM(akute disseminierte Enzephalomyelitis)-ähnlichen Verlaufs beschrieben. Viele Studien berichten eine "Mikrogliaaktivierung“, ohne dass immer genau angegeben wird, wie diese definiert ist und nachgewiesen wurde. Generell ist daher eine internationale Abstimmung zu Mindestanforderungen beim Bericht von „Inflammation“ und "Ischämie/Blutung" sinnvoll, da diese Begriffe bisher zu uneinheitlich verwendet wurden (siehe $\bullet$ Tab. 1). Dieser Umstand macht eine systematische Metaanalyse der bisherigen Daten hierzu 


\begin{tabular}{|c|c|c|c|c|}
\hline Inflammation & $\begin{array}{l}\text { Ischämie/ } \\
\text { Blutungen }\end{array}$ & Sonstiges & $\begin{array}{l}\text { Anzahl } \\
\text { Hirn- } \\
\text { sektionen }\end{array}$ & $\begin{array}{l}\text { Literatur- } \\
\text { quelle }\end{array}$ \\
\hline $\mathrm{MG} \uparrow n=7 / 7$ & $\begin{array}{l}\text { Akute hypoxische } \\
\text { Enzephalopathie } \\
n=2 / 7\end{array}$ & - & 7 & $\begin{array}{l}\text { Deigendesch } \\
\text { et al. (2020) } \\
\text { [14] }\end{array}$ \\
\hline Inflammation $n=4 / 18$ & $\begin{array}{l}\text { Akute globale } \\
\text { Ischämie } n=18 / 18\end{array}$ & - & 18 & $\begin{array}{l}\text { Solomon et al. } \\
\text { (2020) [51] }\end{array}$ \\
\hline $\begin{array}{l}\text { MG } \uparrow \text {, meningeale } \\
\text { T-Zellen } n=34 / 43\end{array}$ & $\begin{array}{l}\text { Akute Ischämie } \\
n=6 / 43\end{array}$ & $\begin{array}{l}\text { Astrogliose } \\
n=37 / 43\end{array}$ & 43 & $\begin{array}{l}\text { Matschke et al. } \\
\text { (2020) [37] }\end{array}$ \\
\hline $\begin{array}{l}\text { ADEM-ähnliche Läsio- } \\
\text { nen }\end{array}$ & $\begin{array}{l}\text { Teils hämorrha- } \\
\text { gisch }\end{array}$ & - & 1 & $\begin{array}{l}\text { Reichard et al. } \\
\text { (2020) [47] }\end{array}$ \\
\hline MG $\uparrow n=13 / 25$ & $\begin{array}{l}\text { Akute Infarkte } \\
n=6 / 33, \text { Blutun- } \\
\text { gen } n=2 / 33\end{array}$ & - & 33 & $\begin{array}{l}\text { Meinhardt et al. } \\
(2021) \text { [38] }\end{array}$ \\
\hline Keine gefunden & $\begin{array}{l}\text { Fokale Ischämie } \\
n=3 / 11 \text {, Blutun- } \\
\text { gen } n=3 / 11\end{array}$ & $\begin{array}{l}\text { Ödem } n=5, \text { Spon- } \\
\text { giose } n=10 / 11\end{array}$ & 11 & $\begin{array}{l}\text { Remmelink } \\
\text { et al. (2020) } \\
\text { [48] }\end{array}$ \\
\hline Keine gefunden & $\begin{array}{l}\text { Globale Ischämie } \\
n=4 / 4\end{array}$ & - & 4 & $\begin{array}{l}\text { Kantonen et al. } \\
\text { (2020) [31] }\end{array}$ \\
\hline $\begin{array}{l}\text { Hirnstammen- } \\
\text { zephalitis } n=1 / 2\end{array}$ & Infarkte $n=2 / 2$ & - & 2 & $\begin{array}{l}\text { Jensen et al. } \\
\text { (2020) [29] }\end{array}$ \\
\hline Keine gefunden & Infarkte $n=2 / 2$ & $\begin{array}{l}\text { Läsionen im Mark- } \\
\text { lager ähnlich zu } \\
\text { Reichard et al. }\end{array}$ & 2 & $\begin{array}{l}\text { Jaunmuktane } \\
\text { et al. (2020) } \\
{[28]}\end{array}$ \\
\hline $\begin{array}{l}\text { Keine MG } \uparrow n=20 / 20 \text {, } \\
\text { T-Zellen } \uparrow n=2 / 20\end{array}$ & Infarkte $n=6 / 20$ & - & 23 & $\begin{array}{l}\text { Bryce et al. } \\
\text { (preprint) [5] }\end{array}$ \\
\hline $\begin{array}{l}\text { Immunzellinfiltration } \\
\text { und MG } \uparrow \text { auf Tran- } \\
\text { skriptionsebene }\end{array}$ & - & - & 2 & $\begin{array}{l}\text { Yang et al. } \\
\text { (preprint) [57] }\end{array}$ \\
\hline
\end{tabular}

- unabhängig von der insgesamt noch geringen Fallzahl - kaum möglich.

Da die Patienten mit COVID-19 häufig an einer bakteriellen Superinfektion und Sepsis versterben, sind vergleichende Untersuchungen mit ähnlichen Krankheitsbildern sinnvoll, fehlen aber in vielen bisher veröffentlichten Studien. Um SARS-CoV-2-spezifische neuropathologische Veränderungen $\mathrm{zu}$ verifizieren, sollten daher alle Befunde sowohl neuropathologisch, pathologisch als auch klinisch erfasst und miteinander korreliert werden.

\section{Peripheres Nervensystem (PNS) und Skelettmuskulatur}

Eine Verminderung oder Veränderung des Riechvermögens gilt als ein typisches Frühsymptom bei SARS-CoV-2-Infektion und wird durch eine Infektion der olfaktorischen Sinnes-, aber auch Stütz- kulatur, die über die Häufigkeit und die Ätiologie einer neuromuskulären Beteiligung bei COVID-19 Auskunft geben können. Möglicherweise werden auch bestehende neuromuskuläre Erkrankungen durch COVID-19 verstärkt [19]. Zusätzlich kann die Beurteilung des peripheren Nervensystems und der Skelettmuskulatur durch oft lange und schwere Krankheitsverläufe mit Folgen, wie z.B. Critical-illness-Myopathie oder Critical-illness-Neuropathie, sowie durch die Wirkung medikamentöser Therapien erschwert werden [9].

\section{Virale Eintrittspforten und deren molekulare Mechanismen}

Die molekularen Mechanismen der SARS-CoV-2-Infektion auf zellulärer Ebene sind noch nicht vollständig geklärt. Es wurde gezeigt, dass SARSCoV-2, ähnlich dem SARS-CoV, das Angiotensin-konvertierende Enzym 2 (ACE2) als Rezeptor verwendet, an den das virale Spike-Glykoprotein bindet ([56]; - Abb. 1). ACE2 könnte zwar als ein primärer Rezeptor in einigen Zelltypen des ZNS vorkommen, die mRNA-Steady-State-Level scheinen jedoch nicht mit dem Infektionspotenzial zu korrelieren, sodass möglicherweise weitere Rezeptoren als Eintrittspforten dienen. Außerdem wurde Heparansulfat als potenzieller Hilfsfaktor der initialen SARS-CoV-2-Bindung an die Zelle identifiziert [10]. Im ZNS weisen Studien auf eine Bindung von SARS-CoV-2 an das Rezeptorprotein Neuropilin-1 (NRP1) hin, welche die Infektiosität von SARSCoV-2 deutlich potenziert. Fraglich ist, ob NRP1 nur zusammen mit ACE2 oder auch als unabhängiger Rezeptor funktioniert $[7,13]$. Im ZNS ist NRP1 im Gegensatz zu ACE2 in verschiedenen Zelltypen, z.B. in Astrozyten, Mikroglia oder Endothelzellen, sehr deutlich detektierbar (sowohl auf mRNA- als auch auf Proteinebene), was den Eintritt in diese Zellen erleichtern könnte [38]. Hier würden weitere Einzelzell-RNASequenzierungsanalysen zur Klärung beitragen [26].

Nach der Aufnahme des Virus in die Wirtszelle ist eine Spaltung des Spikeproteins durch zelluläre Proteasen für die 
Fusion von SARS-CoV-2 mit der Zellmembran nötig. Hier wurde die mögliche Beteiligung der transmembranen Serinprotease 2 (TMPRSS2), Cathepsin B und L sowie Furin gezeigt. Für TMPRSS2 wurde die dafür nötige proteolytische Aktivierung des Spikeproteins bereits mechanistisch aufgeklärt [26].

\section{Infektionsrouten des SARS-CoV- 2 ins ZNS}

Die Invasion der Coronaviren und die Ausbreitung im ZNS kann vermutlich auf zwei Wegen erfolgen: 1. hämatogen oder 2. neurogen (• Abb. 2). Darüber hinaus wird das glymphatische System, bestehend aus olfaktorischen und zervikalen lymphatischen Blutgefäßen, als Infektionsroute diskutiert [3].

\section{Die hämatogene Route}

Viruspartikel aus dem Blutplasma können das ZNS durch rezeptorvermittelte Transzytose über die Blut-Hirn-Schranke (BHS) und die Blut-Liquor-Schranke (BLS) infizieren (• Abb. 2). Da die SARSCoV-2-Viruspartikel einen Durchmesser von ca. $100 \mathrm{~nm}$ haben [1], sind auch die fenestrierten Endothelien der meisten zirkumventrikulären Organe für das Virus nur durch Transzytose durchgängig. In Übereinstimmung mit einer Expression der SARS-CoV2-Rezeptorproteine ACE2 und NRP1 in Endothelzellen konnte SARS-CoV-2 in zerebralen Endothelzellen in Autopsiestudien nachgewiesen werden [38]. Weiterhin wird diskutiert, ob SARSCoV-2 zu einer Schädigung der Endothelbarrieren führt, beispielsweise durch einen systemischen Zytokinsturm [26, 27, 43]. Untersuchungen an Choroid-Plexus-Organoiden/Hirnorganoiden zeigen, dass SARS-CoV-2 einen Tropismus für Epithelzellen des Plexus choroideus aufweist, Neurone und Gliazellen beispielsweise aber weniger deutlich infiziert [27, 43, 46]. Über die Infektion des Plexus-choroideus-Epithels ist eine Verbreitung über den Liquor in viele weitere Gehirnareale denkbar. Systematische, in Kohortenstudien reproduzierte Nachweise von viraler mRNA im Liquor oder Proteinnachweise stehen aber noch aus

Pathologe 2021 · 42:172-182 https://doi.org/10.1007/s00292-021-00924-x

(c) Der/die Autor(en) 2021

N. Ritschel · H. Radbruch · C. Herden · N. Schneider · C. Dittmayer · J. Franz · C. Thomas . G. Silva Boos · A. Pagenstecher · W. Schulz-Schaeffer · C. Stadelmann · M. Glatzel · F. L. Heppner · J. Weis · K. Sohrabi · A. Schänzer · A. Németh · T. Acker · DGNN-Taskforce „CNSCOVID19" • „DEFEAT PANDEMIcs - Neuropathologische Referenzdiagnostik bei COVID-19"

\section{COVID-19: Auswirkungen auf das zentrale und periphere Nervensystem}

\section{Zusammenfassung}

Die gesundheitlichen Auswirkungen der Coronavirus-Krankheit 2019 (COVID-19) durch die Infektion von SARS-CoV-2 (SchweresAkutes-Respiratorisches-Syndrom-Coronavirus 2) werden mit der Ausbreitung der Pandemie immer deutlicher. Neben der Lunge sind auch andere Organe betroffen, welche die Morbidität und Mortalität deutlich beeinflussen können. Insbesondere neurologische Symptome unter Beteiligung des zentralen und peripheren Nervensystems können akute Symptome oder Langzeitfolgen auslösen. Die Mechanismen dieser Neuropathogenese der SARS-CoV-2-Infektion und ihr Zusammenhang mit akuten und chronischen neurologischen Symptomen sind Gegenstand aktueller Studien, die sich mit der Untersuchung einer potenziellen direkten und indirekten Virusinfektion des Nervensystems beschäftigen. In der folgenden Übersichtsarbeit wird der aktuelle Stand über die neuropathologischen Manifestationen, die molekulare Pathogenese, die möglichen Infektionswege im Nervensystem und die systemischen Wirkungen zusammengefasst. Zusätzlich wird ein Überblick über das bundesweite Register CNS-COVID19 und Kooperationen gegeben, die zu einem besseren Verständnis der neurologischen Symptome von COVID-19 beitragen sollen.

Schlüsselwörter

SARS-CoV-2 - Neuropathologie · Nervensystem $\cdot$ Obduktion $\cdot$ Register

\section{COVID-19 and the central and peripheral nervous system}

\section{Abstract}

The health effects of coronavirus disease 2019 (COVID-19) caused by the infection of SARSCoV-2 (severe acute respiratory syndrome coronavirus 2) are becoming increasingly clear as the pandemic spreads. In addition to the lungs, other organs are also affected, which can significantly influence morbidity and mortality. In particular, neurological symptoms involving the central nervous system can lead to acute or long-term consequences. The mechanisms of this neuropathogenesis of SARS-CoV-2 infection and its relation to acute and chronic neurological symptoms are the subject of current studies investigating a potential direct and indirect viral infection of the nervous system. The following review summarizes the current status of neuropathological manifestations, molecular pathogenesis, possible infection pathways in the nervous system, and systemic effects. In addition, an overview of the Germany-wide CNS-COVID19 registry and collaborations is presented, which should contribute to a better understanding of the neurological symptoms of COVID-19.

Keywords

SARS-CoV-2 $\cdot$ Neuropathology $\cdot$ Nervous system · Autopsy $\cdot$ Registry
(• Tab. 2). Darüber hinaus können Coronaviren Leukozyten infizieren, welche in ihrer aktivierten Form die BHS nach dem Prinzip des „leukocyte trafficking“ überqueren können. So könnten diese SARS-CoV-2 als „Trojanisches Pferd“ für den Eintritt ins ZNS dienen. Für diesen Weg liegen aber bisher keine schlüssigen Daten vor [26, 43].

\section{Die neurogene Route}

Eine retrograde neurogene Infektion erfolgt möglicherweise über das olfaktorische System [15, 38]. Damit vereinbar ist ein vermindertes oder verändertes Riechempfinden, welches bei vielen COVID19-Patienten auftritt [4]. Die Rezeptoren ACE2 und TMPRSS2 sind in der Nasenschleimhaut auf mRNA- und Proteinebene nachweisbar, wobei sie sich vorwiegend auf den Epithelzellen und we- 


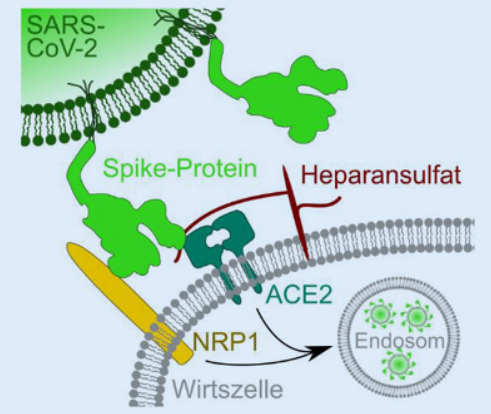

Abb. $1 \Delta$ Eintrittsmechanismen von SARSCoV-2 in die Wirtszelle. SARS-CoV-2 „severe acute respiratory syndrome coronavirus 2", ACE2 Angiotensin-konvertierendes Enzym 2, NRP1 Neuropilin-1

niger auf den olfaktorischen Neuronen finden. Dafür zeigen olfaktorische Neuronen eine deutliche NRP1-Expression [7]. Eine transsynaptische Ausbreitung nach Endozytose und axonalem Transport konnte für die humanen Coronaviren $\mathrm{HCoV}-\mathrm{OC} 43$ und SARS-CoV im Mausmodell bereits gezeigt werden [15]. Daneben könnten weitere Hirnnerven (z.B. N. trigeminus) als Infektionsrouten in das ZNS dienen [38]. Obwohl erste Studien auf eine mögliche neuronale Ausbreitung von SARS-CoV-2 im ZNS hindeuten (•Tab. 2), sind weitere Untersuchungen notwendig, um diesen Weg besser zu verstehen [26].

\section{Indirekte und systemische Effekte von SARS-CoV-2 auf das Nervensystem}

Die neurologischen Symptome und neuropathologischen Veränderungen bei COVID-19-Patienten können durch direkte Virus-induzierte und indirekte, systemische oder therapieinduzierte Effekte verursacht werden.

\section{Organversagen}

Durch ein kardiorespiratorisches Versagen bei COVID-19-Patienten kann es zu einer globalen Hypoxie im ZNS kommen, nachweisbar vor allem in hypoxiesensiblen Arealen wie dem Kleinhirn und dem Hippocampus [26]. Oft ist noch unklar, inwieweit eine direkte Infektion der Organe eine Rolle spielt. In jedem Fall könnten systemische metabolische Veränderungen, die auf einer Funktionseinschränkung verschiedener Organe wie Niere oder Leber beruhen, zur neurologischen Symptomatik beitragen [26].

\section{Autonomes Nervensystem}

Eine besondere Rolle im Kontext von COVID-19 kommt möglicherweise dem autonomen Nervensystem zu. Patienten mit Vorerkrankungen, die mit einer erhöhten Aktivität des sympathischen Nervensystems zusammenhängen, wie beispielsweise arterielle Hypertonie, Diabetes mellitus Typ 2 oder Herzerkrankungen, weisen eine höhere Morbidität und Mortalität auf. Diese könnten einerseits auf eine Hyperaktivierung der ohnehin übermäßig aktiven sympathischen Neuronen, beispielsweise im Hirnstamm, zurückzuführen sein. Andererseits könnte der in diesen Patienten als vermindert aktiv beschriebene neurovagale antiinflammatorische Reflex zur höheren Sterblichkeit beitragen [15]. Darüber hinaus könnte, auch bei Patienten ohne Vorerkrankungen, eine Aktivierung des Hypothalamus zur Aktivierung des autonomen Nervensystems über die Hypothalamus-HypophysenNebennierenrinden-Achse und damit einhergehend $\mathrm{zu}$ einer Immundysregulation führen [25]. In jedem Fall ist noch unklar, inwieweit direkte oder indirekte Effekte der Infektion hier eine Rolle spielen.

Systemische (Hyper-)Inflammation und postinfektiöse Autoantikörper

Im Normalfall löst eine Virusinfektion eine zelluläre Reaktion mit Ausschüttung von Zytokinen (vor allem Interferone [IFN]) aus. SARS-CoV-2 scheint diesen Mechanismus wie viele andere $\mathrm{Vi}$ ren teilweise zu umgehen [55]. Eine Studie zeigte, dass schwer erkrankte Patienten wesentlich geringere IFN- $\alpha$-Level aufwiesen als leicht- und mittelschwer erkrankte Patienten. Gleichzeitig zeigte sich bei diesen Patienten stark erhöhte Werte anderer Zytokine (IL-6, IL-10 und TNF- $\alpha$ ). Dieses Phänomen wird als Zytokinsturm bezeichnet [21]. An seiner Entstehung sind vermutlich dysregulierte myeloide Zellen beteiligt [55]. Vermutlich führt der Zytokinsturm zur Schädigung der BHS und BLS. Somit könnten neben Zytokinen auch Virusbestandteile in Liquor und das Gehirn allgemein gelangen, welche dort in Mikrogliazellen sowie perivaskulären und meningealen Makrophagen eine Immunreaktion auslösen und den systemischen Zytokinsturm verstärken, welcher zusätzlich zur ZNS-Schädigung beiträgt [26, 38].

Darüber hinaus zeigen Studien eine reduzierte Anzahl und/oder veränderte Aktivität von Lymphozyten im peripheren Blut der Patienten, vor allem natürliche Killerzellen sowie CD4- und CD8-T-Zellen, die mit der Schwere der Erkrankung korreliert [55]. Eine andere Studie fand in schwerkranken Patienten vermehrt polyklonale GM-CSF+CD4-T-Zellen, die so auch bei Patienten mit inflammatorischen Autoimmunerkrankungen, unabhängig von COVID19, gefunden wurden [55]. Auch wurden in Patienten hochaffine SARS-CoV2-neutralisierende Antikörper entdeckt, die mit Säugetierepitopen - auch im Gehirn - kreuzreagierten [32]. Diese Autoantikörper könnten auch lange nach einer durchgestandenen SARS-CoV-2Infektion noch für neurologische Spätfolgen wie anhaltender Geruchsverlust oder ein Ermüdungssyndrom („,chronic fatigue“) (mit-)verantwortlich sein.

\section{Hyperkoagulabilität}

Eine erhöhte Gerinnbarkeit des Blutes (Hyperkoagulabilität), mit Embolien und Mikrothromben in einer Vielzahl von Organen, ist ein weiteres Hauptmerkmal schwerer COVID-19-Verläufe ([11]; - Abb.3). Diese Befunde sind gut vereinbar mit ischämischen ZNS-Infarkten als eine gehäufte Komplikation bei COVID-19-Erkrankten (• Tab. 1). Die Pathogenese der gestörten Prokoagulanz-Antikoagulanz-Balance ist nicht abschließend geklärt. Möglicherweise spielt dabei die Aktivierung des Komplementsystems und eine vermehrte Ausschüttung von koagulationsförderndem IL-6 sowie die Rekrutierung von Neutrophilen eine entscheidende Rolle. Mit dem Ziel, Pathogene zu immobilisieren, entlassen Neutrophile „neutrophil 


\begin{tabular}{|c|c|c|}
\hline Methode $^{a}$ & Lokalisation & Literaturquelle \\
\hline RT-qPCR & Lobus frontalis & $\begin{array}{l}\text { Paniz-Mondolfi et al. (2020) [42] } \\
\text { Matschke et al. (2020) [37] } \\
\text { Yang et al. (preprint) [57] } \\
\text { Solomon et al. (2020) [51] }\end{array}$ \\
\hline RT-qPCR & Liquor cerebrospinalis & Moriguchi et al. (2020) [40] \\
\hline RT-qPCR & Medulla oblongata & $\begin{array}{l}\text { Matschke et al. (2020) [37] } \\
\text { Meinhardt et al. (2021) [38] } \\
\text { Solomon et al. (2020) [51] }\end{array}$ \\
\hline RT-qPCR & Ganglion trigeminale & Meinhardt et al. (2021) [38] \\
\hline RT-qPCR & Bulbus olfactorius & $\begin{array}{l}\text { Meinhardt et al. (2021) [38] } \\
\text { Solomon et al. (2020) [51] }\end{array}$ \\
\hline RT-qPCR & Cerebellum & Meinhardt et al. (2021) [38] \\
\hline $\begin{array}{l}\text { Sequenz- } \\
\text { ierung }\end{array}$ & Liquor cerebrospinalis & Zhou et al. (2020) [58] \\
\hline $\mathrm{IHC}$ & $\begin{array}{l}\text { Olfaktorische sensorische } \\
\text { Neurone (Epithelium olfac- } \\
\text { torium) }\end{array}$ & $\begin{array}{l}\text { Cantuti-Castelvetri et al. (2020) [7] } \\
\text { Meinhardt et al. (2021) [38] }\end{array}$ \\
\hline IHC & N. olfactorius & $\begin{array}{l}\text { Meinhardt et al. (2021) [38] } \\
\text { Solomon et al. (2020) [51] }\end{array}$ \\
\hline IHC & $\begin{array}{l}\text { N. vagus, N. glossopharyn- } \\
\text { geus }\end{array}$ & Matschke et al. (2020) [37] \\
\hline IHC & Cerebellum & Meinhardt et al. (2021) [38] \\
\hline IHC & Gefäßendothel & Meinhardt et al. (2021) [38] \\
\hline IHC & Cortex cerebri & $\begin{array}{l}\text { Song et al. (preprint) [52] } \\
\text { Yang et al. (preprint) [57] }\end{array}$ \\
\hline IHC & Meningen & $\begin{array}{l}\text { Yang et al. (preprint) [57] } \\
\text { Meinhardt et al. (2021) [38] }\end{array}$ \\
\hline IHC & Plexus choroideus & Yang et al. (preprint) [57] \\
\hline IHC & Medulla oblongata & $\begin{array}{l}\text { Matschke et al. (2020) [37] } \\
\text { Meinhardt et al. (2021) [38] }\end{array}$ \\
\hline \multicolumn{3}{|c|}{$\begin{array}{l}\text { IHC Immunhistochemie, } R T-q P C R \text { Reverse-Transkriptase quantitative Polymerase-Kettenreaktion } \\
\text { aEin eindeutiger elektronenmikroskopischer Nachweis von SARS-CoV-2 im zentralen Nervensystem ist } \\
\text { unserer Meinung nach bisher noch ausstehend }\end{array}$} \\
\hline
\end{tabular}

extracellular traps" (NETs, extrazelluläre Netze aus kondensiertem Chromatin und antimikrobiellen Proteinen), welche Ausgangspunkt einer Thrombusbildung sein können [39]. Weiterhin tragen diffuse, endotheliale Veränderungen mit Entzündungsanzeichen wie eine erhöhte Von-Willebrand-Faktor-Konzentration zur Entstehung von Thromben bei [11]. Die bisherigen Erkenntnisse weisen darauf hin, dass sich Hyperinflammation und Hyperkoagulabilität bei COVID19-Patienten gegenseitig verstärken.

\section{Therapiefolgen}

Aufgrund des erhöhten Risikos von multimorbiden Patienten für einen schweren COVID-19-Krankheitsverlauf haben Patienten, die an COVID-19 versterben, häufig weitere, v.a. internistische

\section{Modelle zur Untersuchung der Effekte einer SARS-CoV-2- Infektion auf das ZNS und PNS}

Um die Infektions-, Verbreitungs- und Schädigungsmechanismen von SARSCoV-2 im ZNS besser zu verstehen und auch potenzielle Therapien $\mathrm{zu}$ testen, bedarf es je nach konkreter Fragestellung geeigneter In-vitro- und In-vivoModelle.

\section{In-vitro-Modelle}

Die meisten bisher eingesetzten etablierten Zelllinien, z. B. Vero E6 (Nierenepithelzellen aus grüner Meerkatze), HEK 293T (humane Nierenepithelzellen), Huh7 (aus humanem hepatozellulärem Karzinom), Caco-2 (aus humanem kolorektalen Karzinom) oder Calu-3 (aus humanem Lungenkarzinom), sind nicht ZNS- oder PNS-spezifisch und können daher nur begrenzt für ZNS-spezifische Fragestellungen verwendet werden [35, 50, 54]. Hingegen sind neuronale Kulturen, Neurosphären und 3D-GehirnOrganoide aus induzierten pluripotenten humanen Stammzellen gut geeignet, um die Effekte einer SARS-CoV-2-Infektion auf Zellen des ZNS in vitro zu untersuchen [6, 8, 27, 43, 46, 52]. Dabei konnte die Infizierbarkeit neuronaler Progenitorzellen sowie von Neuronen und Plexusepithelzellen gezeigt werden. Über eine aktive virale Replikation in Neuronen wird dabei unterschiedlich berichtet.

\section{In-vivo-Modelle}

Als für eine SARS-CoV-2-Infektion empfängliche Tiermodelle werden vorrangig Mäuse, Hamster, Frettchen und nichthumane Primaten (NHP) genutzt [17, 18, 24, 33, 50]. Die Suszeptibilität der Tiermodelle determiniert sich dabei durch die Bindungsaffinität zum tierspezifischen ACE2 oder der Proteaseaktivität für die Spaltung des viralen Spikeproteins. Da Mäuse aufgrund von Unterschieden zwischen murinem und humanem ACE2 per se nicht empfänglich für eine Infektion mit humanem SARS-CoV-2 sind [59], werden transgene Mauslinien mit Expression des 


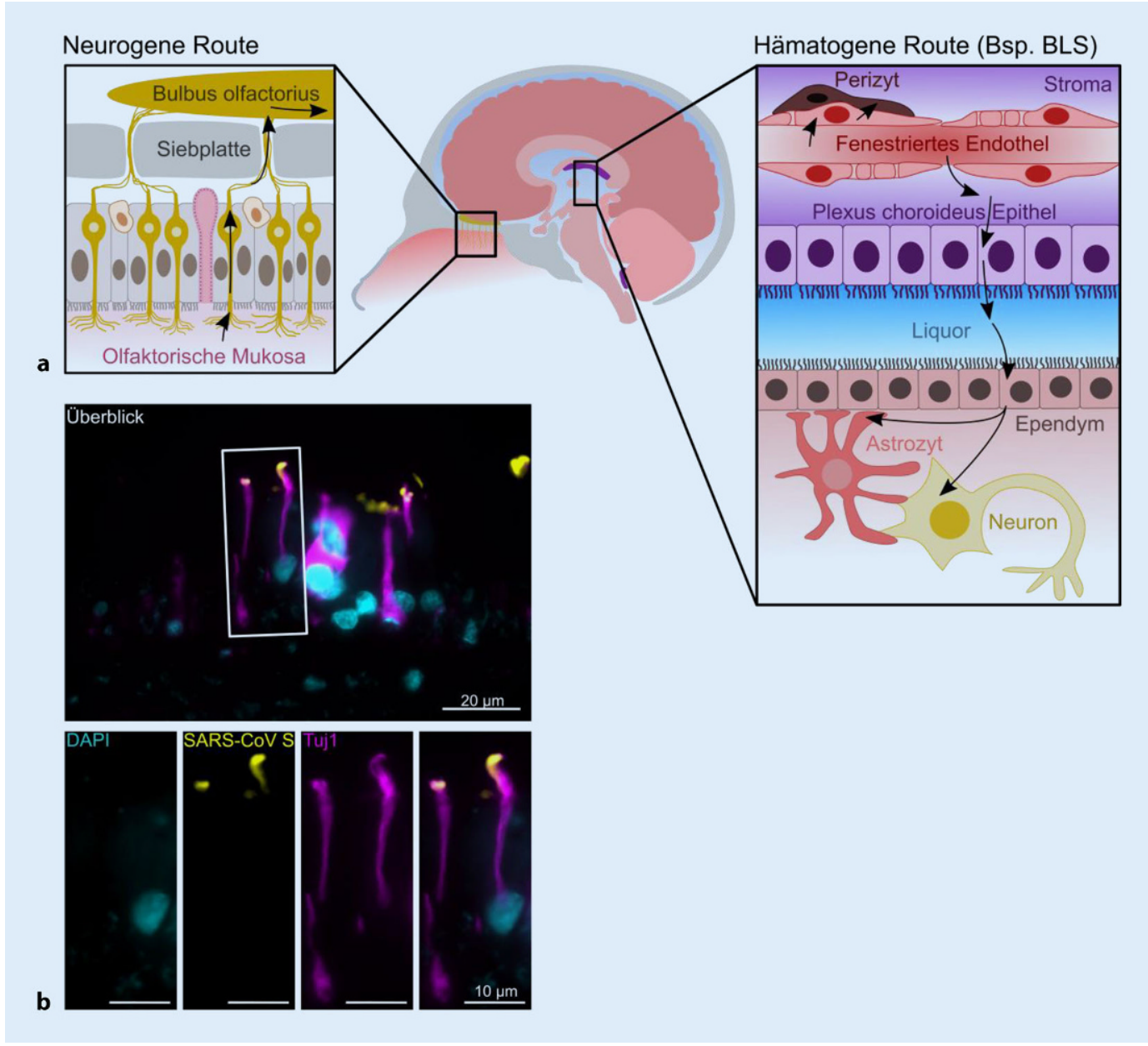

Abb. $2 \triangleleft$ Mögliche Infektionsrouten für SARS-CoV-2 ins zentrale Nervensystem am Beispiel der olfaktorischen Routen (neurogene Route) und einer Penetration der Blut-Liquor-Schranke (BLS; hämatogene Route; (a)). Immunfluoreszenzfärbung von olfaktorischen Neuronen (Tuj1+, lila) und SARSCoV-2 (gelb) in der olfaktorischen Mukosa (b). DAPI 4',6-Diamidin-2-phenylindol (Kernfärbung, blau), SARS-CoV- 2 "severe acute respiratory syndrome coronavirus $2^{\prime \prime}$

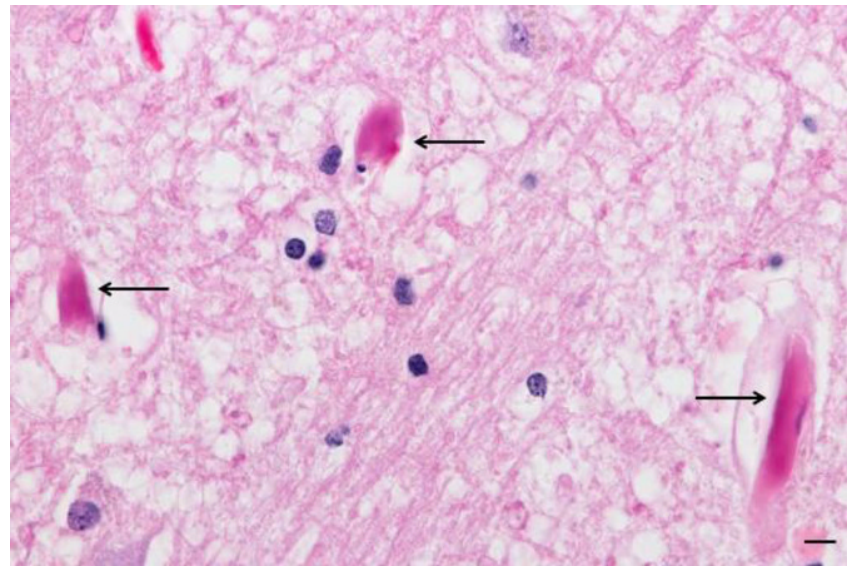

Abb. $3<$ Intravaskuläre Mikrothromben (Pfeile) im Bereich des Thalamus eines an COVID-19 verstorbenen Patienten. HE-Färbung. Messbalken: $10 \mu \mathrm{m}$

humanen ACE2 unter verschiedenen Promotoren und damit auch erweitertem Organtropismus verwendet [17, 24]. Dies führt bei Krt18-hACE2 Mäusen und betaActin-hACE2-Mäusen zu einer schweren Pneumonie mit typischer Inflammation, Thrombosen und auch Anosmie [22, 24]. Bei diesen Linien tritt bei SARS-CoV- und SARS-CoV-
2-Infektionen auch eine Invasion des Gehirns und z. T. Enzephalitis auf, was bei COVID-19 in dieser Ausprägung nicht beobachtet wird. Weiterhin konnte durch eine virale transiente Transduktion eine Expression von hACE2 gezielt im Respirationstrakt erreicht werden, was $\mathrm{zu}$ schweren Pneumonien mit hohen Viruslasten führt, wie auch bei COVID-
19 [22, 24]. Eine Adaptation von SARSCoV-2 an die Maus gelang durch die Adaptation der Rezeptorbindedomäne des Spikeproteins über Mauspassagen sowie die Einführung gezielter Mutationen, auch über CRISPR/Cas-Technologien, was die Verwendung von Wildtypmäusen erlaubt $[22,24]$. Hierbei treten schwerere Krankheitsverläufe - auch mit ARDS als bei hACE2-transgenen Mäusen auf.

Hamster gelten auch als geeignetes Tiermodell, um die SARS-CoV-2-Infektion im oberen und unteren Respirationstrakt mit entsprechenden histopathologischen Veränderungen abzubilden [17, 24]. Dies trifft auch für Frettchen zu, die vor allem auch für Studien zur direkten und indirekten Übertragung des Erregers wertvolle Ergebnisse liefern [17, 24, 33].

Als NHPs werden Rhesusaffen, Makaken und Grüne Meerkatzen verwendet, die meist auch einen milden COVID-19Verlauf mit leichten klinischen Symptomen, Virusnachweis und histopatholo- 


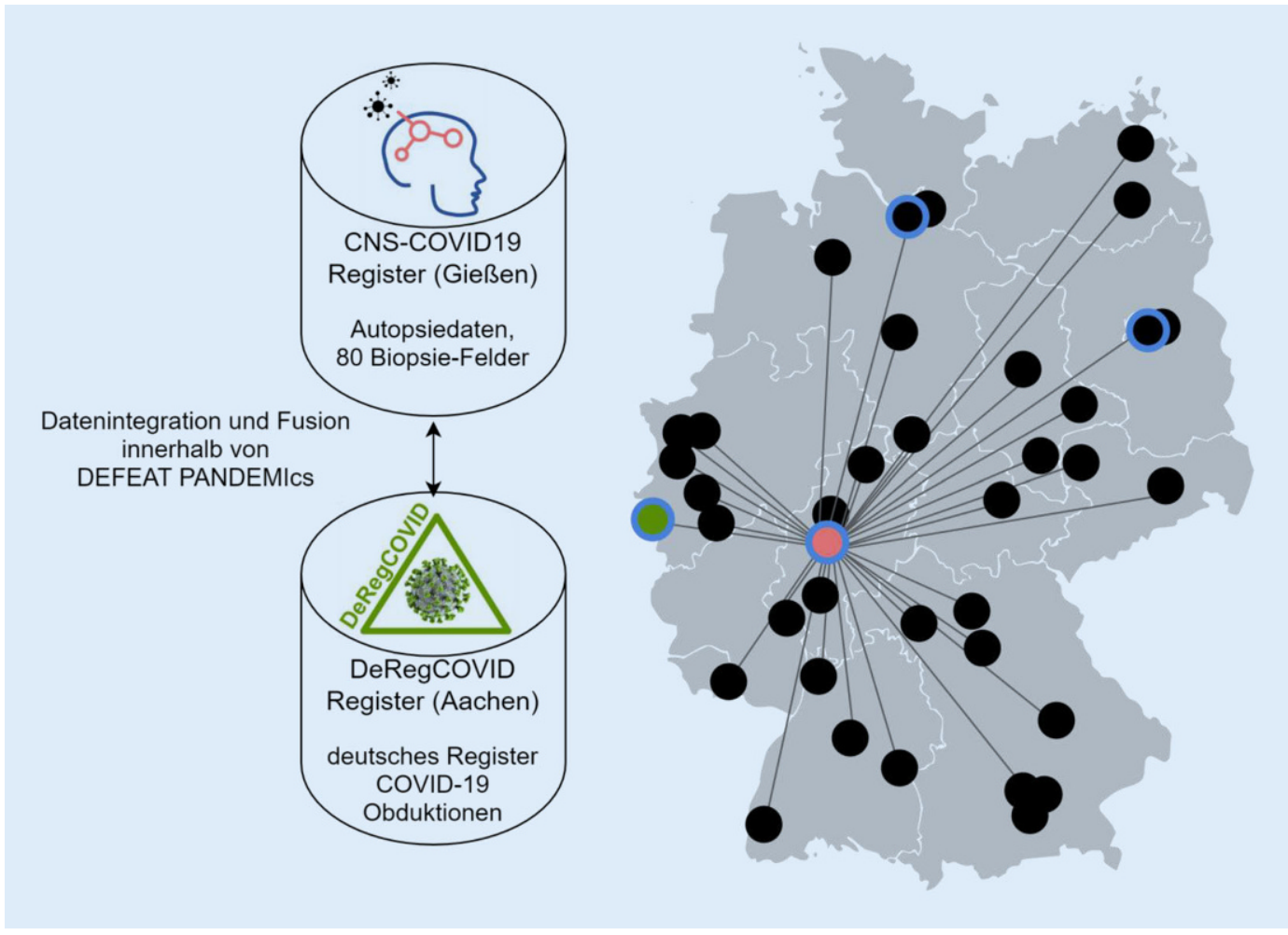

Abb. $4<$ Register CNSCOVID19. Neuropathologische Autopsiedaten werden fachübergreifend im deutschen Register COVID19 (DeRegCovid) zusammengeführt und als homogene Datenbasis zugänglich für die wissenschaftliche Gemeinschaft vereint. Unterstützend wirken die innerhalb von DEFEATPANDEMICs gegründeten neuropathologischen Referenzzentren (blau hinterlegt)

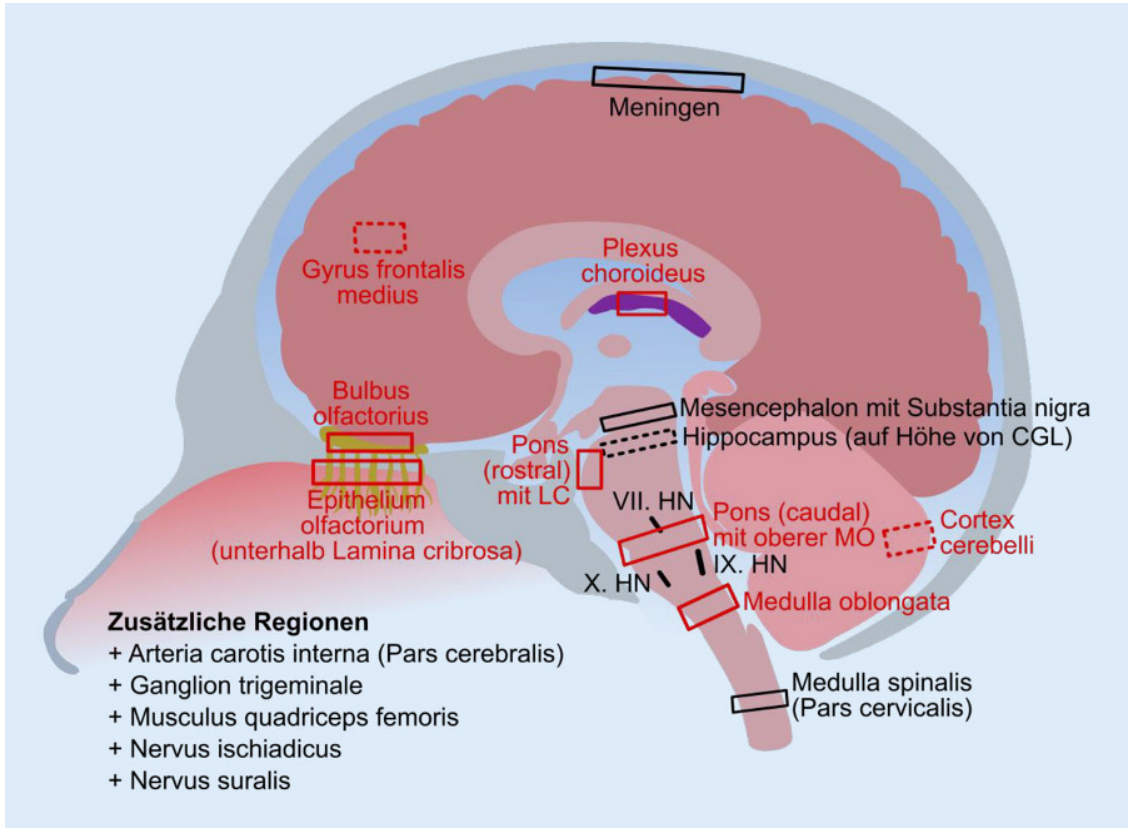

Abb. $5 \Delta$ Probenentnahme bei Obduktionen aus dem zentralen Nervensystem. Im Rahmen des COVID-19-Register der Deutschen Gesellschaft für Neuropathologie und Neuroanatomie e. V. wurde ein Kerndatensatz (rot) zur neuropathologischen Untersuchung bei COVID-19-erkrankten Patienten definiert, um eine Vereinheitlichung an den verschiedenen Standorten zu gewährleisten. Weitere interessante Regionen können optional entnommen werden (schwarz). (Gestrichelte Linie = Lokalisation liegt nicht in gezeigter Schnittebene). CGL Corpus geniculatum laterale, HN Hirnnerv, LC Locus coeruleus gischen Läsionen im Respirationstrakt aufweisen. Ein Zytokinsturm mit systemischer Entzündungsreaktion wie bei COVID-19 wurde jedoch nicht beobachtet. Die Infektion von alten Grünen Meerkatzen und Rhesusaffen führt jedoch zu schwereren Krankheitsverläufen und kann so auch als Modell für Altersdisposition bei COVID-19verwendet werden $[22,24]$.

\section{COVID-19-Register}

Zum schnelleren und besseren Verständnis einer Beteiligung des ZNS und PNS bei COVID-19 werden systematische Untersuchungen von Gewebeproben ausreichend großer Patientenkohorten benötigt. Aus diesem Grund hat die Deutschen Gesellschaft für Neuropathologie und Neuroanatomie (DGNN e. V.) das deutschlandweite Register CNSCOVID19 zur Zusammenführung von multizentrisch vorliegenden klinischen Daten und Obduktionsbefunden und dezentralem Biosampling gegründet. Dieses steht der wissenschaftlichen $\mathrm{Ge}$ meinschaft zur Verfügung und vernetzt sich mit vorhandenen klinischen Patientenregistern. CNS-COVID19 sammelt 
Tab. 3 Neuropathologischer Datensatzzur Gewebeentnahme bei COVID-19-Sektionen.XAngabe der Areale und der funktionalen Zugehörigkeit dieser Areale (olfaktorisch, gustatorisch, kardiorespiratorisch, PNS)

\begin{tabular}{|c|c|c|c|c|}
\hline Areal & Olfaktorisch & Gustatorisch & $\begin{array}{l}\text { Kardio-re- } \\
\text { spiratorisch }\end{array}$ & PNS \\
\hline $\begin{array}{l}\text { Epithelium olfactorium (unterhalb } \\
\text { Lamina cribrosa) }\end{array}$ & $\mathrm{x}$ & & & \\
\hline Bulbus olfactorius & $\mathrm{x}$ & & & \\
\hline \multicolumn{5}{|l|}{$\begin{array}{l}\text { Hippocampus (auf Höhe von Corpus } \\
\text { geniculatum laterale) }\end{array}$} \\
\hline \multicolumn{5}{|l|}{ Gyrus frontalis medius } \\
\hline \multicolumn{5}{|l|}{ Mesencephalonmit Substantia nigra } \\
\hline $\begin{array}{l}\text { Pons (rostral) mit Locus coeruleus } \\
\text { (oberhalb des V. HN) }\end{array}$ & & & $x$ & \\
\hline $\begin{array}{l}\text { Pons (caudal) mit oberer Medulla ob- } \\
\text { longata }\end{array}$ & & $x$ & $x$ & \\
\hline Medulla oblongata & & $\mathrm{x}$ & $x$ & \\
\hline Nervus facialis (VII. HN) & & $\mathrm{x}$ & $x$ & \\
\hline Nervus glossopharyngeus (IX. HN) & & $x$ & $x$ & \\
\hline Nervus vagus (X. HN) & & $\mathrm{x}$ & $x$ & \\
\hline Medulla spinalis (Pars cervicalis) & & & $x$ & \\
\hline \multicolumn{5}{|l|}{ Cortex cerebelli } \\
\hline \multicolumn{5}{|l|}{ Meningen (Leptomeningen) } \\
\hline \multicolumn{5}{|l|}{ Plexus choroideus } \\
\hline Arteria carotis interna (Pars cerebralis) & & & $x$ & \\
\hline Ganglion trigeminale & & & & $x$ \\
\hline Musculus quadriceps femoris ${ }^{\mathrm{a}}$ & & & & $\mathrm{x}$ \\
\hline Nervus ischiadicus ${ }^{b}$ & & & & $x$ \\
\hline Nervus suralis ${ }^{b}$ & & & & $\mathrm{x}$ \\
\hline \multicolumn{5}{|c|}{$\begin{array}{l}\text { Kursiv }=\text { Kerndatensatz, steil = zusätzliche interessante Regionen } \\
\text { HN Hirnnerv, PNS peripheres Nervensystem } \\
\text { aZZusätzlich Fixierung mit } 6 \% \text { Glutaraldehyd (GA) } \\
\text { 'ZZusätzlich Fixierung mit 4\% GA }\end{array}$} \\
\hline
\end{tabular}

Autopsiedaten und zugehörige Metadaten von über 35 universitären und außeruniversitären (neuropathologischen) Instituten. Der bestehende intersektorale Austausch wurde im Rahmen des DEFEAT-PANDEMIcs-Projekts des „Netzwerks Universitätsmedizin“ noch erweitert (• Abb. 4). Dieses Projekt zielt auf eine deutschlandweite systematische Zusammenführung von Daten und Erkenntnissen im Pandemiefall durch den Aufbau eines nationalen Obduktionsnetzwerkes ab. Extract-TransformLoad(ETL)-Strecken, die Teil eines eigens erstellten Datenintegrationssystems sind, harmonisieren die Informationen aus unterschiedlichen Quellen und vereinen sie als homogene Datenbasis im DeRegCovid-Register, einem nationalen fachübergreifenden COVID-19-Autopsieregister an der Universitätsklinik sammelt europaweit Daten zu Epidemiologie und Krankheitsverlauf von Patienten mit COVID-19 ([49]; https:// leoss.net). Die Studie „pooled analysis of neurologic disorders manifesting in intensive care" (PANDEMIC) der Deutschen Gesellschaft für Neurointensivund Notfallmedizin (DGNI) betrachtet die Charakteristika von COVID-19-Patienten mit neurologischen Manifestationen und gleichzeitigem schweren Verlauf (https://www.dgni.de/forschung/ ignite-initiative-klinischer-multizenterstudien.html). Die institutions- und fachübergreifende Zusammenführung aller Daten ist hilfreich für die Pathogeneseforschung bei COVID-19-Erkrankung und bildet eine exzellente Grundlage für den schnellen Aufbau vergleichbarer Infrastrukturen bei zukünftigen Pandemien.

\section{Empfehlungen zur Proben- entnahme und Fixierung}

Die bisherigen Ergebnisse zeigen die Vorzüge einer Untersuchung an ausreichend großen Patientenkohorten im Vergleich $\mathrm{zu}$ einzelnen Fallstudien. Im Rahmen der COVID-19 Task Force der DGNN und dem Aufbau von CNS-COVID19 wurden Empfehlungen für die standardisierte Entnahme relevanter Gehirnareale sowie zusätzlich von peripheren Nerven und Skelettmuskeln zusammengestellt (• Tab. 3; - Abb. 5; www.cns-covid19. de). Die Gewebeproben sollten - auch zur Virusinaktivierung - ausreichend lange in Formalin ${ }^{1}$ [23] bzw. Glutaraldehyd für eine Semidünnschnittpräparation und ultrastrukturelle Analyse fixiert werden. Für letztere sind neben 2-6\% gepuffertem Glutaraldehyd (GA) insbesondere zur Primärfixierung auch gepufferte Gemische mit Formaldehyd (FA) zu empfehlen (z. B. 1\% FA und 2,5\%

html). Perspektivisch ist es sinnvoll, weitere mit Bezug auf COVID-19-Erkrankungen und damit verbundene pathologische Merkmale entwickelte klinische Register in die Datenintegration mit einzubeziehen. Das von der DGI (Deutsche Gesellschaft für Infektiologie) und dem DZIF (Deutsches Zentrum für Infektionsforschung) konzipierte „lean european open survey for SARS-CoV-2 infected patients“ (LEOSS)

\footnotetext{
$110 \%$ gepufferte Formalinlösung, enthält $4 \%$ Formaldehyd (FA): mind. $48 \mathrm{~h}$ bei Paraffineinbettung (die übliche Paraffineinwirkung von mind. $2 \mathrm{~h}$ bei $60-65^{\circ} \mathrm{C}$ verstärkt die Virusinaktivierung); ohne Hitzeeinwirkung besser längere Fixierungszeit [21]. Das Center for Disease Control der USA empfiehlt $72 \mathrm{~h}$ in $10 \%$ gepufferter Formalinlösung (https://www.cdc. gov/coronavirus/2019-ncov/hcp/guidancepostmortem-specimens.html).
} 


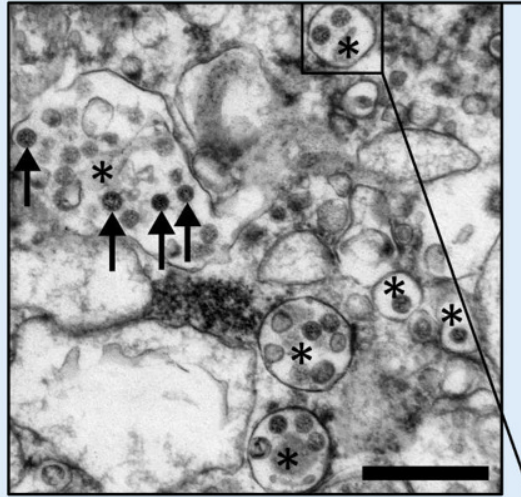

a

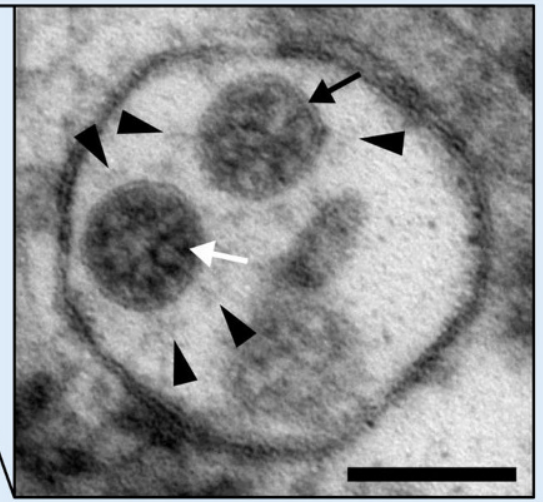

b

Abb. 6 A Charakteristische Ultrastruktur einer SARS-CoV-2-infizierten Zelle in der Lunge. a Stern = Membrankompartimente mit intrazellulären Viruspartikeln, Pfeile=Coronaviren, Messbalken: $500 \mathrm{~nm}$. b schwarzer Pfeil= Biomembran eines Viruspartikels, weißer Pfeil = granuläres Ribonukleoprotein, schwarze Pfeilspitzen = Krone, Messbalken: $100 \mathrm{~nm}$. SARS-CoV-2 "severe acute respiratory syndrome coronavirus 2"

GA). Es sind kleine (ca. 2-3 mm Kantenlänge) Gewebestücke zu entnehmen, um eine gute Fixierung und Morphologie zu gewährleisten. Zur Erfassung fokaler Infektionen sollten möglichst aus verschiedenen Regionen der Organe Proben entnommen werden, welche in vielen Schnittebenen aufgearbeitet und aufmerksam am Elektronenmikroskop durchgemustert werden sollten.

Für eine ultrastrukturelle Suche nach Viren sollten speziell Proben aus Geweben mit möglichst hoher, durch RTqPCR nachgewiesener Viruslast gewonnen werden, ggf. auch wenn diese ein hohes postmortales Intervall aufweisen $[16,38]$, primär kryoasserviert oder in Formalin fixiert wurden oder bereits als FFPE(formalinfixiertes und paraffineingebettetes)-Gewebe vorliegen. FFPEGewebe ermöglicht es außerdem, gezielt Infektionsfoci (Nachweis mittels Immunhistochemie oder In-situ-Hybridisierung) zu stanzen und anschließend für Elektronenmikroskopie weiter aufzuarbeiten [38]. Durch Darstellung morphologisch intakter Viruspartikel kann weiterhin eine wichtige Validierung der anderen Techniken erfolgen. Additive wie Gerbsäure können die Darstellung der Spikes deutlich verbessern [34].

Intrazelluläre Viruspartikel (• Abb. 6) sind typischerweise in Membrankompartimenten lokalisiert (• Abb. 6a, Sternchen). Trotz starker Autolyse des Gewe-

bes lassen sich Coronaviren gut identifizieren (• Abb. 6a, Pfeile). Die Viruspartikel lassen sich durch ihre Substruktur mit Biomembranen (- Abb. 6b, schwarzer Pfeil), granulärem Ribonukleoprotein (RNP; Abb. 6b, weißer Pfeil) und ihrer Größe von ca. $100 \mathrm{~nm}$ von anderen Strukturen abgrenzen. Einzelne infizierte Zellen mit dutzenden bis hunderten Viruspartikeln können als schnittinterne Positivkontrolle fungieren und so die Identifizierung von einzelnen $\mathrm{Vi}$ ruspartikeln in anderen Zellen erleichtern. Diverse morphologisch ähnliche Strukturen sollten gezielt von möglichen Viruspartikeln abgegrenzt werden $[16,25,38]$. Wichtig hierbei, vermutlich auch Grund vieler publizierter Fehleinordnungen, ist die Unterscheidung der Ultradünnschnittpräparation, in welcher die „Krone“ häufig nur angedeutet (• Abb. 6b, Pfeilspitzen) erscheint, von der Negativkontrastierung, in welcher sie als charakteristisches morphologisches Merkmal sehr prominent ist. Weiterhin können Vesikel innerhalb von Zisternen des endoplasmatischen Retikulums, ebenfalls mit granulärer Innenstruktur, Schwierigkeiten in der Abgrenzung bereiten $[25,38]$. Jedoch imponieren diese mit deutlich prominenteren und größeren Granula (17-23 nm vs. 9-16 nm) im Vergleich zum RNP der Coronaviren [25].
Da sowohl die FA- als auch GAFixierung zur zuverlässigen Abtötung von SARS-CoV-2 führt [30], kann das Gewebe in einem Standard-Pathologielabor aufgearbeitet und an innerhalb von DEFEAT-PANDEMIcs unterstützte Referenzzentren versandt werden ([20]; - Abb. 4). Für komplexere Methoden empfiehlt es sich, das Gewebe in Formalin zu fixieren und in Sucrose gefroren $\mathrm{zu}$ asservieren (ohne Paraffineinbettung) [53].

\section{Ausblick}

Die neurologischen Manifestationen bei COVID-19 sind bisher noch unzureichend verstanden. Eine respiratorische Insuffizienz und Hyperkoagulabilität können das Risiko eines ischämischen oder hämorrhagischen Infarktes erhöhen. Es wurden bereits bei mehreren Patienten mit COVID-19 intravaskuläre Mikrothromben im ZNS nachgewiesen. Zusätzlich kann eine systemische Hyperinflammation (Zytokinsturm) diese Veränderungen verstärken. $\mathrm{Ob}$ und wie genau eine direkte (virale) oder indirekte Beteiligung des ZNS kausal mit einem schweren Krankheitsverlauf von COVID-19 zusammenhängt, kann erst nach systematischen neuropathologischen Untersuchungen größerer Patientenkohorten beantwortet werden. Hinweise auf eine SARS-CoV-2-Infektion in der Medulla oblongata deuten auf eine mögliche Rolle bei der kardiorespiratorischen Insuffizienz hin, da hier wichtige Nervenkerne zur Regulation des Atemzentrums und $\mathrm{CO}_{2}$-Chemorezeptoren lokalisiert sind. Ebenfalls könnte eine virale Infektion die Funktion spezifischer $\mathrm{O}_{2}$-Chemosensoren im Glomus caroticum beeinflussen. Weitere wichtige Fragen sind noch nicht abschließend geklärt. Welcher Mechanismen bedient sich das Virus, um ins ZNS zu gelangen? Wie ist die Pathogenese der beschriebenen ZNS-Schädigungen? Sind sie direkter Natur oder auf die systemische Reaktion des Körpers zurückzuführen? Während es schon verschiedene Studien zu COVID-19-Auswirkungen auf das ZNS gibt, fehlen systematische morphologische Untersuchungen des peripheren Nervensystems und der Skelettmusku- 
latur fast gänzlich. Zur Beantwortung der genannten Fragen kommt in der Grundlagenforschung und translationalen Forschung der Weiterentwicklung geeigneter In-vitro- und In-vivo-Modelle eine wichtige Rolle zu. Insbesondere eine systematische Erfassung von Gewebe- und Autopsieproben klinisch gut charakterisierter Patientenkohorten, die Entwicklung standardisierter Gewebeasservierungsprotokolle bei Autopsien unter Einhaltung der besonderen Hygienevorschriften sowie die Entwicklung und Etablierung von Methoden zum feingeweblichen Virusnachweis und „deep phenotyping" werden essenziell sein, um die Rolle der Beteiligung des ZNS und PNS für den Krankheitsverlauf bei COVID-19 näher zu charakterisieren, neue Behandlungsmöglichkeiten $\mathrm{zu}$ entwickeln und Langzeitfolgen abzuschätzen.

\section{Fazit für die Praxis}

- Patienten mit COVID(coronavirus disease)-19-Erkrankungen können eine Beteiligung des zentralen Nervensystems (ZNS) und des peripheren Nervensystems (PNS) aufweisen, die einen Einfluss auf Morbidität und Mortalität hat.

- Gehäuft treten hypoxämische Veränderungen inkl. ZNS-Infarkte auf, welche vermutlich durch Mikrothromben bei Hyperkoagulationssyndrom und Zytokinsturm verursacht werden.

- Ein direkter Virusnachweis von SARSCoV-2 (,severe acute respiratory syndrome coronavirus $2^{\prime \prime}$ ) im ZNS konnte mithilfe immunhistochemischer Methoden und molekularer Analysen erbracht werden. Als Eintrittspforte in das Gehirn werden neurogene oder hämatogene Ausbreitungswege diskutiert.

- Zum besseren Verständnis der Pathogenese der Beteiligung des ZNS und PNS bei COVID-19-Patienten müssen Gewebeproben ausreichend großer Patientenkohorten untersucht werden. Eine autoptische Untersuchung und systematische Erfassung von an/mit COVID-19 verstorbenen $\mathrm{Pa}$ tienten in einem Register ist daher dringend erforderlich.
- Systematische neuropathologische Untersuchungen des PNS und der Skelettmuskulatur fehlen bisher.

\begin{tabular}{ll} 
Korrespondenzadresse \\
$\begin{array}{l}\text { Prof. Dr. T. Acker } \\
\text { Institut für Neuropathologie, } \\
\text { Justus-Liebig-Universität } \\
\text { Gießen }\end{array}$ \\
$\begin{array}{l}\text { Arndtstraße 16, 35392 Gie- } \\
\text { Ben, Deutschland } \\
\text { till.acker@ } \\
\text { patho.med.uni-giessen.de }\end{array}$ \\
\hline
\end{tabular}

Danksagung. Wir bedanken uns bei Dr. Michael Laue und Gudrun Holland (Robert Koch-Institut, Berlin) für Gewebepräparationen elektronenmikroskopischer Proben und bei der Core Facility Elektronenmikroskopie der Charité für Unterstützung bei der Aufnahme der Bilder. Diese Arbeit wurde unterstützt durch das Bundesministerium für Bildung und Forschung im Rahmen des Netzwerkes Universitätsmedizin (DEFEAT PANDEMIcs, 01KX2021).

Mitglieder der DGNN-Taskforce "CNS-COVID19“. H. Radbruch; C. Herden; A. Pagenstecher; W. SchulzSchaeffer; C. Stadelmann; T. Acker

Mitglieder der „DEFEAT PANDEMIcs - Neuropathologische Referenzdiagnostik bei COVID-19“. H. Radbruch; M. Glatzel; F.L. Heppner; J. Weis; T. Acker

\section{Einhaltung ethischer Richtlinien}

Interessenkonflikt. N. Ritschel, H. Radbruch, C. Herden, N. Schneider, C. Dittmayer, J. Franz, C. Thomas, G. Silva Boos, A. Pagenstecher, W. Schulz-Schaeffer, C. Stadelmann, M. Glatzel, F.L. Heppner, J. Weis, K. Sohrabi, A. Schänzer, A. Németh und T. Acker geben an, dass kein Interessenkonflikt besteht.

Für diesen Beitrag wurden von den Autoren keine Studien an Menschen oder Tieren durchgeführt. Für die aufgeführten Studien gelten die jeweils dort angegebenen ethischen Richtlinien.

Open Access. Dieser Artikel wird unter der Creative Commons Namensnennung 4.0 International Lizenz veröffentlicht, welche die Nutzung, Vervielfältigung, Bearbeitung, Verbreitung und Wiedergabe in jeglichem Medium und Format erlaubt, sofern Sie den/die ursprünglichen Autor(en) und die Quelle ordnungsgemäß nennen, einen Link zur Creative Commons Lizenz beifügen und angeben, ob Änderungen vorgenommen wurden.

Die in diesem Artikel enthaltenen Bilder und sonstiges Drittmaterial unterliegen ebenfalls der genannten Creative Commons Lizenz, sofern sich aus der Abbildungslegende nichts anderes ergibt. Sofern das betreffende Material nicht unter der genannten Creative Commons Lizenz steht und die betreffende Handlung nicht nach gesetzlichen Vorschriften erlaubt ist, ist für die oben aufgeführten Weiterverwendungen des Materials die Einwilligung des jeweiligen Rechteinhabers einzuholen.
Weitere Details zur Lizenz entnehmen Sie bitte der Lizenzinformation auf http://creativecommons.org/ licenses/by/4.0/deed.de.

\section{Literatur}

1. Bar-On YM, Flamholz A, Phillips Ret al (2020) SARSCoV-2 (COVID-19) by the numbers. Elife 9:e57309

2. Belani P, Schefflein J, Kihira S et al (2020) COVID19 is an independent risk factor for acute ischemic stroke. AJNR Am J Neuroradiol 41:1361-1364

3. Bostancıklığlu M (2020) SARS-CoV2 entry and spread in the lymphatic drainage system of the brain. Brain Behav Immun 87:122-123

4. Brann DH, Tsukahara T, Weinreb C et al (2020) Nonneuronal expression of SARS-CoV-2 entry genes in the olfactory system suggests mechanisms underlying COVID-19-associated anosmia. Sci Adv 6:eabc5801

5. Bryce C, Grimes Z, Pujadas E et al (preprint) Pathophysiology of SARS-CoV-2: targeting of endothelial cells renders a complex disease with thrombotic microangiopathy and aberrant immune response. The Mount Sinai COVID-19 autopsy experience. medRxiv. https://doi.org/10. 1101/2020.05.18.20099960

6. Bullen CK, Hogberg HT, Bahadirli-Talbott $A$ et al (2020) Infectability of human BrainSphere neurons suggests neurotropism of SARS-CoV-2. ALTEX 37:665-671

7. Cantuti-Castelvetri L, Ojha R, Pedro LD et al (2020) Neuropilin-1 facilitates SARS-CoV-2 cell entry and infectivity. Science 370:856-860

8. Caporale N, Testa G (2020) COVID-19 lessons from the dish: dissecting CNS manifestations through brain organoids. Embo J 40(2):e107213

9. Caress JB, Castoro RJ, Simmons Z et al (2020) COVID-19-associated Guillain-barre syndrome: the early pandemic experience. Muscle Nerve 62:485-491

10. Clausen TM, Sandoval DR, Spliid CB et al (2020) SARS-coV-2 infection depends on cellular heparan sulfate and ACE2. Cell 183:1043-1057.e15

11. Cordon-Cardo C, Pujadas E, Wajnberg A et al (2020) COVID-19: staging of a new disease. Cancer Cell 38:594-597

12. Dalakas MC (2020) Guillain-Barre syndrome: the first documented COVID-19-triggered autoimmune neurologic disease: More to come with myositis in the offing. Neurol Neuroimmunol Neuroinflamm 7(5):e781

13. Daly JL, Simonetti B, Klein K et al (2020) Neuropilin-1 is a host factor for SARS-CoV-2 infection. Science 370:861-865

14. Deigendesch N, Sironi L, Kutza M et al (2020) Correlates of critical illness-related encephalopathy predominate postmortem COVID-19 neuropathology. Acta Neuropathol 140(4):583-586

15. Desforges $M$, Le Coupanec A, Dubeau $P$ et al (2019) Human Coronaviruses and other respiratory viruses: underestimated opportunistic pathogens of the central nervous system? Viruses 12:14

16. Dittmayer C, Meinhardt J, Radbruch H et al (2020) Why misinterpretation of electron micrographs in SARS-CoV-2-infected tissue goes viral. Lancet 396:e64-e65

17. Ehaideb SN, Abdullah ML, Abuyassin B et al (2020) Evidence of a wide gap between COVID-19 in humans and animal models: a systematic review. Crit Care 24:594 
18. Genzel L, Adan R, Berns A et al (2020) How the COVID-19 pandemic highlights the necessity of animal research. Curr Biol 30:4328

19. Guidon AC, Amato AA (2020) COVID-19 and neuromuscular disorders. Neurology 94:959-969

20. Haddock E, Feldmann F (2017) Validating the inactivation effectiveness of chemicals on Ebola virus. Methods Mol Biol 1628:251-257

21. Hadjadj J, Yatim N, Barnabei L et al (2020) Impaired type I interferon activity and inflammatory responses in severe COVID-19 patients. Science 369:718-724

22. Harrison AG, Lin T, Wang P (2020) Mechanisms of SARS-CoV-2 transmission and pathogenesis. Trends Immunol 41:1100-1115

23. Henwood AF (2020) Coronavirus disinfection in histopathology. JHistotechnol 43:102-104

24. Hewitt JA, Lutz C, Florence WC et al (2020) ACTIVating resources for the COVID-19 pandemic: in vivo models for vaccines and therapeutics. Cell Host Microbe 28:646-659

25. Hopfer H, Herzig MC, Gosert R et al (2020) Hunting coronavirus by transmission electron microscopy-a guide to SARS-CoV-2-associated ultrastructural pathology in COVID-19 tissues. Histopathology 78:358-370

26. ladecola C, Anrather J, Kamel H (2020) Effects of COVID-19 on the Nervous System. Cell 183:16-27e1

27. Jacob F, Pather SR, Huang WK et al (2020) Human pluripotent stem cell-derived neural cells and brain organoids reveal SARS-coV-2 neurotropism predominates in choroid plexus epithelium. Cell Stem Cell 27:937-950e9

28. Jaunmuktane $Z$, Mahadeva U, Green A et al (2020) Microvascular injury and hypoxic damage: emerging neuropathological signatures in COVID19. Acta Neuropathol 140(3):397-400

29. Jensen et al (2020) Neuropathological findings in two patients with fatal COVID-19. Neuropathol Appl Neurobiol 47(1):17-25

30. Jureka AS, Silvas JA, Basler CF (2020) Propagation, inactivation, and safety testing of SARS-CoV-2. Viruses 12:622

31. Kantonen J, Mahzabin S, Mäyränpää MI et al (2020) Neuropathologic features of four autopsied COVID-19 patients. Brain Pathol 30(6):1012-1016

32. Kreye J, Reincke SM, Pruss H (2020) Do crossreactive antibodies cause neuropathology in COVID-19? Nat Rev Immunol 20:645-646

33. Lakdawala SS, Menachery VD (2020) The search for a COVID-19 animal model. Science 368:942-943

34. Laue M, Kauter A, Hoffmann T et al (2020) Morphometry of SARS-CoV and SARS-CoV-2 particles in ultrathin sections of infected Vero cell cultures. bioRxiv

35. Leist SR, Schafer A, Martinez DR (2020) Cell and animal models of SARS-CoV-2 pathogenesis and immunity. Dis Model Mech 13:dmm046581

36. Li CW, Syue LS, Tsai YS et al (in press) Anosmia andolfactory tractneuropathy in a case of COVID19. J Microbiol Immunol Infect. https://doi.org/10. 1016/j.jmii.2020.05.017

37. Matschke J, Lütgehetmann M, Hagel $C$ et al (2020) Neuropathology of patients with COVID19 in Germany: a post-mortem case series. Lancet Neurol 19(11):919-929

38. Meinhardt J, Radke J, Dittmayer C et al (2021) Olfactory transmucosal SARS-CoV-2 invasion as a port of Central Nervous System entry in COVID-19 patients. Nat Neurosci 24:168-175

39. Middleton EA, He XY, Denorme F et al (2020) Neutrophil extracellular traps contribute to immunothrombosis in COVID-19 acute respiratory distress syndrome. Blood 136:1169-1179

40. Moriguchi T, Harii N, Goto J et al (2020) A first case of meningitis/encephalitis associated with SARSCoronavirus-2. Int JInfect Dis 94:55-58

41. Nannoni S, De Groot R, Bell S et al (2020) Stroke in COVID-19: a systematic review and meta-analysis. Int J Stroke 16(2):137-149

42. Paniz-Mondolfi A, Bryce C, Grimes Z et al (2020) Central nervous system involvement by severe acute respiratory syndrome coronavirus-2 (SARS CoV-2). J Med Virol 92:699-702

43. Pellegrini L, Albecka A, Mallery DL et al (2020) SARS-CoV-2 infects the brain choroid plexus and disrupts the blood-CSF barrier in human brain organoids. Cell Stem Cell 27(55):951-961.e5

44. Pezzini A, Padovani A (2020) Lifting the mask on neurological manifestations of COVID-19. Nat Rev Neurol 16:636-644

45. Pitscheider L, Karolyi M, Burkert FR et al (2020) Muscle involvement in SARS-CoV-2 infection. Eur Neurol.https://doi.org/10.1111/ene.14564

46. Ramani A, Muller L, Ostermann PN et al (2020) SARS-CoV-2 targets neurons of 3D human brain organoids. Embo J 39:e106230

47. Reichard RR, Kashani KB, Boire NA (2020) Neuropathology of COVID-19: a spectrum of vascular and acute disseminated encephalomyelitis (ADEM)like pathology. Acta Neuropathol 140(1):1-6

48. Remmelink M, De Mendonça R, D'Haene $\mathrm{N}$ et al (2020) Unspecific post-mortem findings despite multiorgan viral spread in COVID-19 patients. Crit Care 24(1):495

49. Ruthrich MM, Giessen-Jung C, Borgmann S et al (2020) COVID-19 in cancer patients: clinical characteristics and outcome-an analysis of the LEOSS registry. Ann Hematol 100:383-393

50. Sanclemente-Alaman I,Moreno-JimenezL, BenitoMartin MS et al (2020) Experimental models for the study of central nervous system infection by SARS CoV-2. Front Immunol 11:2163

51. Solomon IH, Normandin E, Bhattacharyya S et al (2020) Neuropathological Features of Covid-19. N Engl J Med 383(10):989-992

52. Song E, Zhang C, Israelow B et al (2020) Neuroinvasion of SARS-CoV-2 in human and mouse brain. bioRxiv. https://doi.org/10.1101/ 2020.06.25.169946

53. Sountoulidis A, Liontos A, Nguyen HP et al (2020) SCRINSHOT, a spatial method for single-cell resolution mapping of cell states in tissue sections. bioRxiv

54. Takayama K (2020) In vitro and animal models for SARS-coV-2 research. Trends Pharmacol Sci 41:513-517

55. Vabret N, Britton GJ, Gruber C et al (2020) Immunology of COVID-19: current State of the Science. Immunity 52:910-941

56. Yan R, Zhang Y, Li Y et al (2020) Structural basis for the recognition of SARS-CoV-2 by full-length human ACE2. Science 367:1444-1448

57. Yang AC, Kern F, Losada PM et al (preprint) Broad transcriptional dysregulation of brain and choroid plexus cell types with COVID-19. bioRxiv. https:// doi.org/10.1101/2020.10.22.349415

58. Zhou L, Zhang M, Wang J et al (2020) Sars-Cov-2: Underestimated damage to nervous system. Travel Med Infect Dis 36:101642

59. Zhou P, Yang XL, Wang XG et al (2020) A pneumonia outbreak associated with a new coronavirus of probable bat origin. Nature 579:270-273
Möchten Sie einen Beitrag für Der Pathologe einreichen?

Wir freuen uns, wenn Sie unsere Zeitschrift Der Pathologe mitgestalten.

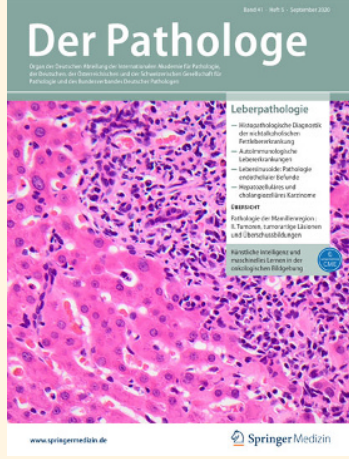

Für folgende Rubriken können Manuskripte eingereicht werden:

- Übersichten

- Originalien

- Kausitiken

Um Ihnen bei der Manuskripterstellung behilflich zu sein, haben wir für unsere Autor*innen ausführliche Leitfäden und Musterbeiträge für die verschiedenen Rubriken zusammengestellt. Diese und weitere Hinweise zur Manuskripterstellung finden Sie online unter dem Menüpunkt „Hinweise für Autoren" unter www.derpathologe.de Bitte laden Sie Ihren fertigen Beitrag in unserem Editorialmanager (www.editorialmanager.com/depa/) hoch. Der zuständige Schriftleiter wird automatisch informiert.

\section{Übersichten:}

Prof. Dr. W. Roth, Mainz

wilfried.roth@unimedizin-mainz.de

\section{Originalien / Kasuistiken}

Prof. Dr. M. Gaida

Matthias.Gaida@unimedizin-mainz.de

Sollten Sie noch Fragen zur Manuskriptgestaltung haben, wenden Sie sich bitte an die Redaktion:

Gabriele Staab

gabriele.staab@springernature.com

Wir freuen uns auf Ihre Beitrag! 